\title{
The FengYun-3C radio occultation sounder GNOS: a review of the mission and its early results and science applications
}

\author{
Yueqiang Sun ${ }^{1,2,3}$, Weihua Bai ${ }^{1,2,3}$, Congliang Liu ${ }^{1,2}$, Yan Liu ${ }^{4}$, Qifei Du ${ }^{1,2,3}$, Xianyi Wang ${ }^{1,2}$, Guanglin Yang ${ }^{5}$, \\ Mi Liao ${ }^{5}$, Zhongdong Yang ${ }^{5}$, Xiaoxin Zhang ${ }^{5}$, Xiangguang Meng ${ }^{1,2}$, Danyang Zhao ${ }^{1,2}$, Junming Xia ${ }^{1,2}$, \\ Yuerong Cai ${ }^{1,2}$, and Gottfried Kirchengast $t^{6,2,1}$ \\ ${ }^{1}$ Beijing Key Laboratory of Space Environment Exploration, National Space Science Center, \\ Chinese Academy of Sciences (NSSC/CAS), Beijing, China \\ ${ }^{2}$ Joint Laboratory on Occultations for Atmosphere and Climate (JLOAC) of NSSC/CAS, Beijing, China, and University of \\ Graz, Graz, Austria \\ ${ }^{3}$ School of Astronomy and Space Science, University of Chinese Academy of Sciences, Beijing, China \\ ${ }^{4}$ National Meteorological Center, Chinese Meteorological Administration, Beijing, China \\ ${ }^{5}$ National Satellite Meteorological Center, Chinese Meteorological Administration, Beijing, China \\ ${ }^{6}$ Wegener Center for Climate and Global Change (WEGC) and Institute for Geophysics, \\ Astrophysics, and Meteorology/Institute of Physics, University of Graz, Graz, Austria
}

Correspondence: Congliang Liu (liucongliang1985@gmail.com) and Weihua Bai (bjbwh@163.com)

Received: 25 October 2017 - Discussion started: 15 January 2018

Revised: 25 July 2018 - Accepted: 7 August 2018 - Published: 23 October 2018

\begin{abstract}
The Global Navigation Satellite System (GNSS) Occultation Sounder (GNOS) is one of the new-generation payloads on board the Chinese FengYun 3 (FY-3) series of operational meteorological satellites for sounding the Earth's neutral atmosphere and ionosphere. FY-3C GNOS, on board the FY-3 series C satellite launched in September 2013, was designed to acquire setting and rising radio occultation (RO) data by using GNSS signals from both the Chinese BeiDou Navigation Satellite System (BDS) and the US Global Positioning System (GPS). So far, the GNOS measurements and atmospheric and ionospheric data products have been validated and evaluated and then been used for atmosphere- and ionosphere-related scientific applications.

This paper reviews the FY-3C GNOS instrument, RO data processing, data quality evaluation, and preliminary research applications according to the state-of-the-art status of the FY3C GNOS mission and related publications. The reviewed data validation and application results demonstrate that the FY-3C GNOS mission can provide accurate and precise atmospheric and ionospheric GNSS (i.e., GPS and BDS) RO profiles for numerical weather prediction (NWP), global climate monitoring (GCM), and space weather research (SWR). The performance of the FY-3C GNOS product quality eval-
\end{abstract}

uation and scientific applications establishes confidence that the GNOS data from the series of FY-3 satellites will provide important contributions to NWP, GCM, and SWR scientific communities.

\section{Introduction}

The global navigation satellite system (GNSS) radio occultation (RO) technique (Melbourne et al., 1994; Ware et al., 1996) for sounding the Earth's neutral atmosphere and ionosphere was demonstrated by the proof-of-concept Global Positioning System/Meteorology (GPS/MET) mission launched in 1995 (Ware et al., 1996; Kursinski et al., 1996; Kuo et al., 1998) as well as the following GNSS RO missions: the Challenging Mini-satellite Payload (CHAMP; Wickert et al., 2001, 2002); the Constellation Observing System for Meteorology, Ionosphere and Climate (COSMIC; Anthes et al., 2000, 2008; Schreiner et al., 2007), the Gravity Recovery and Climate Experiment (GRACE; Beyerle et al., 2005; Wickert et al., 2005); and the Meteorological Operational (MetOp) satellites (Edwards and Pawlak, 2000; Luntama et al., 2008). These missions have demonstrated the 


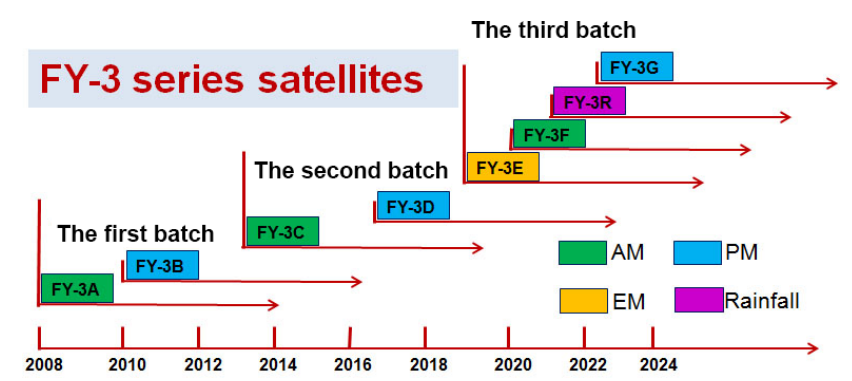

Figure 1. Timeline of FY-3 series satellites. The FY-3 series satellites are the Chinese second-generation polar-orbiting meteorological satellites including AM (morning), PM (afternoon), and EM (evening) orbits, and rainfall types of satellites, which have been/will be launched in three batches (source: Sun et al., 2017).

unique properties of the GNSS RO technique - such as high vertical resolution, high accuracy, all-weather capability, and global coverage (Ware et al., 1996; Gorbunov et al., 1996; Rocken et al., 1997; Leroy, 1997; Steiner et al., 1999) - and long-term stability and consistency of different RO mission observations (Foelsche et al., 2009, 2011). Therefore, GNSS RO data products (i.e., bending angle, refractivity, temperature, pressure, water vapor, and ionospheric electron density profiles) have been widely used for numerical weather prediction (NWP; e.g., Healy and Eyre, 2000; Kuo et al., 2000; Healy and Thepaut, 2006; Aparicio and Deblonde, 2008; Cucurull and Derber, 2008; Poli et al., 2008; Huang et al., 2010; Le Marshall et al., 2010; Harnisch et al., 2013), global climate monitoring (GCM; e.g., Steiner et al., 2001, 2009, 2011, 2013; Schmidt et al., 2005, 2008, 2010; Loescher and Kirchengast, 2008; Ho et al., 2009, 2012; Foelsche et al., 2011a; Lackner et al., 2011), and space weather research (SWR; Anthes, 2011; Anthes et al., 2008; Arras et al., 2008; Brahmanandam et al., 2012; Pi et al., 1997; Wickert, 2004; Yue et al., 2015).

The development of GNSSs such as China's BeiDou Navigation Satellite System (BDS), Russia's GLObal NAvigation Satellite System (GLONASS), and the European Galileo system has significantly enhanced the availability and capacity of the GPS-like satellites, which will make GNSS RO even more attractive in the future (Bai et al., 2018). These new GNSS satellites, together with planned low Earth orbit (LEO) missions, will offer many more RO observations in the future (Wang et al., 2015; Cai et al., 2017). One of these LEO missions is China's GNSS Occultation Sounder (GNOS) on board the FengYun 3 series C (FY-3C) satellite, which was successfully launched on 23 September 2013 (Wang et al., 2013, 2014; Bai et al., 2014b, 2016; Liao et al., 2015, 2016a, b; Wang et al., 2016; Du et al., 2016).

The FY-3C GNOS mission was designed and developed by the National Space Science Center, Chinese Academy of Sciences (NSSC/CAS), to sound the Earth's neutral atmosphere and ionosphere by using both the BDS and GPS sig-

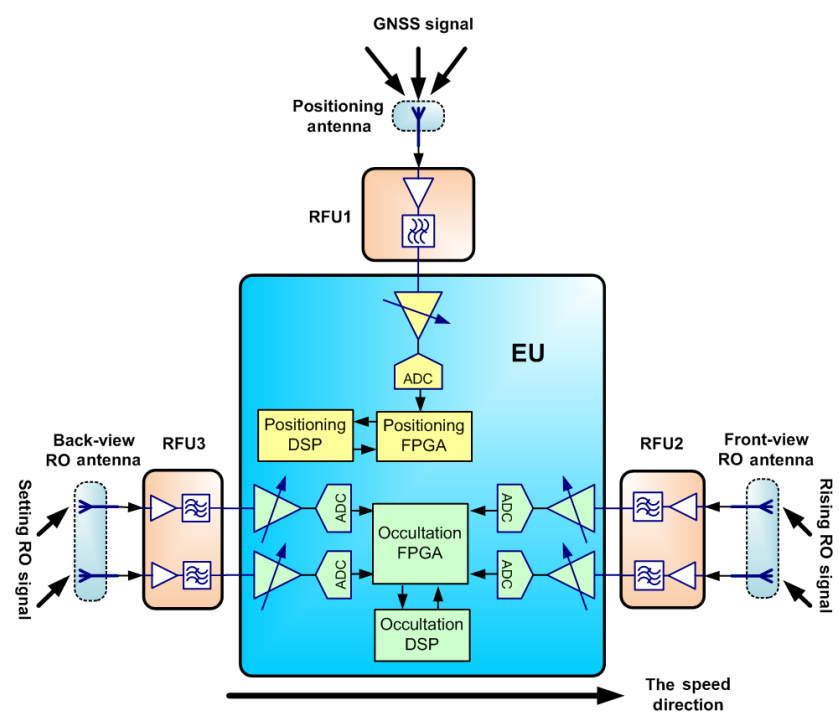

Figure 2. Design (functional block diagram) of GNOS instrument (source: Du et al., 2016).

nals (Wang et al., 2015; Bai et al., 2018). The FY-3C satellite is the first BDS- and GPS-compatible RO sounder with a state-of-the-art RO receiver - GNOS (Bai et al., 2012, 2014a; Wang et al., 2015; Du et al., 2016). The following FY-3 series of operational meteorological satellites (Fig. 1) will continue to carry GNOS as a major payload. The next one of these satellites is FY-3D, which was launched on 15 November 2017 (Liao et al., 2016b; Yang et al., 2017; Sun et al., 2017).

The FY-3C GNOS instrument consists of three antennas; three radio frequency units (RFUs); and an electronic unit (EU), which uses high-dynamic, high-sensitivity signal acquisition and tracking techniques (Fig. 2). The three RFUs are installed close to their corresponding antennas by using sharp cavity filters, to reduce the loss of the cable between antennas and RFUs. The EU is the major component of GNOS, which accomplishes the GNSS remote-sensing signals' acquisition and tracking as well as the real-time positioning and carrier phase observations (Wang et al., 2015). In FY-3C GNOS design, the different features of BDS and GPS signals have been taken into account, and it can observe both the neutral atmosphere and ionosphere by using both BDS and GPS signals.

As shown in Fig. 2, the FY-3C GNOS instrument involves a positioning antenna, a rising occultation antenna, and a setting occultation antenna as part of its physical structure. In terms of electrical structure, the FY-3C GNOS involves five antennas because each occultation antenna has an ionosphere occultation antenna and an atmosphere occultation antenna (Bai et al., 2014a, b). 
The positioning antenna is a wide-beam, low-gain antenna pointing toward zenith, which can track six BDS and eight GPS satellites simultaneously. Its measurements are used for real-time navigation, positioning, and the LEO satellites' precise orbit determination (POD) in post-processing.

The front-view (along the satellite velocity direction) occultation antenna and back-view (satellite anti-velocity direction) occultation antenna are used for rising and setting occultation event tracking, respectively. The FY-3C GNOS can track four BDS and six GPS occultation events simultaneously. The atmosphere occultation antennas have a pattern that is wide in azimuth and narrow in elevation. A gain of approximately $10 \mathrm{dBi}$ is reached over the coverage range of about $\pm 35^{\circ}$ in azimuth and about $\pm 7.5^{\circ}$ in elevation (Bai et al., 2014a; Du et al., 2016).

The EU of FY-3C GNOS is based on a field-programmable gate array (FPGA) and digital signal processor (DSP) framework. After filtering and down-conversion in the RFU, the signals are digitally down-converted with an analog-todigital converter (ADC) and then sampled at a high rate and transmitted to the channel processor of the EU, where the GNOS accomplishes navigation, positioning and occulting GNSS satellite prediction and selection, signal acquisition and tracking, and data handling. An ultra-stable oscillator (USO) is used as a reference oscillator with highly stable frequency $\left(1 \mathrm{~s}\right.$ Allan deviation of $10^{-12}$ ), in order to retrieve atmospheric measurements with high accuracy (Du et al., 2016; Sun et al., 2017). It also allows data users to invert the excess phase by using the zero-difference method (Beyerle et al., 2005; Bai et al., 2018).

The FY-3C GNOS is a multi-frequency receiver with BDS and GPS compatibility, BDS B1 and B2 closed-loop tracking, GPS L2 codeless-mode operation for P code, GPS L2C closed-loop tracking, and GPS L1 C/A closed-loop and open-loop tracking capabilities. The capability for both BDS and GPS increases the number of transmitting sources and promises significant enhancements in total throughput of measurements. The FY-3C GNOS receiver measures the following observable parameters: for each tracked GPS satellite, L1 C/A code phase, L1 carrier phase, L1 signal amplitude, L2 P code phase, L2C code phase (if present), L2 carrier phase, and L2 signal amplitude; and for each tracked BDS satellite, B1I code phase, B1 carrier phase, B1 signal amplitude, B2I code phase, B2 carrier phase, and B2 signal amplitude (Bai et al., 2014a).

In the lower part of the troposphere, where highly dynamic signal conditions are frequently encountered due to the strong atmospheric modulations, the GPS L1 signal is tracked in open loop in parallel with the closedloop tracking. In open-loop tracking, the signal is downconverted using a numerically controlled oscillator, which generates a frequency given by an onboard Doppler model pre-calculated in GNOS without feedback from the received signal (Sokolovskiy, 2001; Sokolovskiy et al., 2009). Particularly, for the rising occultation, an a priori range model of the atmospheric delay (Ao et al., 2009) is also calculated on board the GNOS. The baseband signal is then sampled at a rate of $100 \mathrm{~Hz}$. For the COSMIC and MetOp missions, the sampling rate of open-loop tracing is $50 \mathrm{~Hz}$ (Sokolovskiy, 2001; Sokolovskiy et al., 2007, 2009) and $1000 \mathrm{~Hz}$ (von Engeln et al., 2009), respectively. The performance of the COSMIC mission proves that a $50 \mathrm{~Hz}$ open-loop sampling rate is sufficient to monitor the troposphere (Sokolovskiy, 2001; Sokolovskiy et al., 2007, 2009), while MetOp uses $1000 \mathrm{~Hz}$ to do a detailed spectrum analysis of the lower troposphere. Indeed, the higher the sampling rate, the more detailed the atmospheric information that can be obtained. Compliant with the FY-3C satellite downlink capability, FY-3C GNOS adopts a $100 \mathrm{~Hz}$ open-loop sampling rate, which is proven to be sufficient to capture the signals modulated by the atmosphere dynamics and uncertainties of the Doppler model. The designed parameters of FY-3C GNOS are summarized in Table 1; it can be seen that some parameters of the FY-3C GNOS are comparable to those of COSMIC (Rocken et al., 2000) or MetOp/GNSS Receiver for Atmospheric Sounding (GRAS; Loiselet et al., 2000).

After this introduction to the topic and the GNOS instrument, the paper is structured as follows. Section 2 provides a description of FY-3C GNOS data processing and data products. Section 3 describes the validation and evaluation of FY3C GNOS data. Section 4 presents the GNOS RO data applications. Finally, a summary and conclusions are given in Sect. 5.

\section{FY-3C GNOS data processing and data products}

The FY-3C satellite flies in a sun-synchronous polar orbit of inclination $98.8^{\circ}$, mean altitude $836 \mathrm{~km}$, and orbital period $101.5 \mathrm{~min}$. Therefore, GNOS can observe the troposphere, stratosphere, and ionosphere from the Earth surface to around $800 \mathrm{~km}$ altitude. As a multi-GNSS receiver, GNOS has the capability of observing the phases and amplitudes of radio waves from GPS and BDS satellites as they are occulted by the Earth's atmosphere. From the raw GNOS observations, accurate and precise vertical bending angle profiles are obtained in the troposphere, stratosphere, and ionosphere. Based on the bending angles, profiles of atmospheric and ionospheric refractivity are calculated. The refractivity is a function of temperature, pressure, water vapor pressure, and electron density, so the refractivity profiles can be used to derive profiles of temperature and water vapor in the troposphere, temperature in the stratosphere, and electron density in the ionosphere. The operational processing procedure and the product levels of the FY-3C GNOS RO data are shown in Fig. 3. 
Table 1. Main parameters of the FY-3C GNOS instrument (source: Bai et al., 2014; Liao et al., 2016b).

\begin{tabular}{ll}
\hline Parameters & Content \\
\hline GNSS signals & GPS L1, L2; BDS B1, B2 \\
\hline Channel numbers & Positioning: 8 ; occultation: 6 (GPS), 4 (BDS) \\
\hline Sampling rate & $\begin{array}{l}\text { Positioning \& ionosphere occultation: } 1 \mathrm{~Hz} \\
\text { Atmosphere occultation: closed loop 50 Hz, } \\
\text { open loop } 100 \mathrm{~Hz}\end{array}$ \\
\hline Output observations & Type: L1C/A, L2C, L2P/ B1I, B2I \\
\hline Contents: pseudo-range/carrier phase/SNR \\
\hline The peak gain of occultation antenna & $10 \mathrm{dBi}\left(\mathrm{azimuth}: \pm 35^{\circ} ;\right.$ horizontal: $\left.\pm 7.5^{\circ}\right)$ \\
\hline Pseudo-range precision & $\leq 30 \mathrm{~cm}$ \\
\hline Carrier phase precision & $\leq 2 \mathrm{~mm}$ \\
\hline Real-time positioning precision & $\leq 10 \mathrm{~m}$ \\
\hline Total weight & $\leq 14 \mathrm{~kg}$ \\
\hline Total power & $\leq 40 \mathrm{~W}$ \\
\hline Equivalent noise temperature & $250 \mathrm{~K}$ \\
\hline Signal bandwidth & GPS P code: $20.46 \mathrm{MHz}$ \\
\hline
\end{tabular}

\subsection{FY-3C GNOS mission system architecture}

As shown in Fig. 3, the FY-3C GNOS mission system consists of three major segments, i.e., GNSS satellite segment, LEO satellite segment, and ground segment. The GNSS segment is composed of the GPS system and the (currently still regional) BDS system. The latter includes five geostationary orbit (GEO) satellites, five inclined geosynchronous orbit (IGSO) satellites, and four medium Earth orbit (MEO) orbit satellites available to conduct radio occultation. The LEO satellite segment is composed of the FY-3C satellite carrying the GNOS RO receiver. The ground segment consists of a data processing center in Beijing and five ground stations, located in Beijing, Wulumuqi, Guangzhou, Jiamusi, and Kiruna. The ground stations are mainly used to receive observed data from the FY-3C satellite and then transmit them to the data processing center. In addition, in the ground segment, auxiliary information provided by the international GNSS service (IGS) stations - such as the GPS/BDS precise orbits, clock files, Earth orientation parameters, and the coordinates and measurements of the ground stations - are also needed.

\subsection{FY-3C GNOS Level 0 data preparation}

In total there are 12 instrument payloads on board the FY$3 \mathrm{C}$ satellite, and their observed data are downloaded to the ground data stations and then transferred to the data process- ing center in Beijing. At the data processing center, firstly the raw observed data are decrypted and decompressed, and then the data packets are classified and stored in 12 different specific storage spaces, according to the number of different instrument payloads. One of the 12 data packets is the binary format FY-3C GNOS observations, mainly including phase and signal-to-noise ratio (SNR) measurements, and these raw data are defined as the Level 0 data.

\subsection{FY-3C GNOS Level 1 data processing}

The unpacking and interpretation program module verifies and revises the data package format of the FY-3C Level 0 raw data and then unpacks them into seven packages, i.e., GPS positioning package, GPS ionospheric occultation package, GPS atmospheric closed-loop occultation package, GPS atmospheric open-loop occultation package, BDS positioning package, BDS ionospheric occultation package, and BDS atmosphere occultation package; finally the program processes and stores the data according to the naming rules and data storage principles. The format conversion program module subsequently converts the data into Receiver-Independent Exchange Format (RINEX) or Network Common Data Form (NetCDF) format. According to the time period of the observed data, the auxiliary data acquisition program module automatically downloads the BDS and GPS ephemeris and 


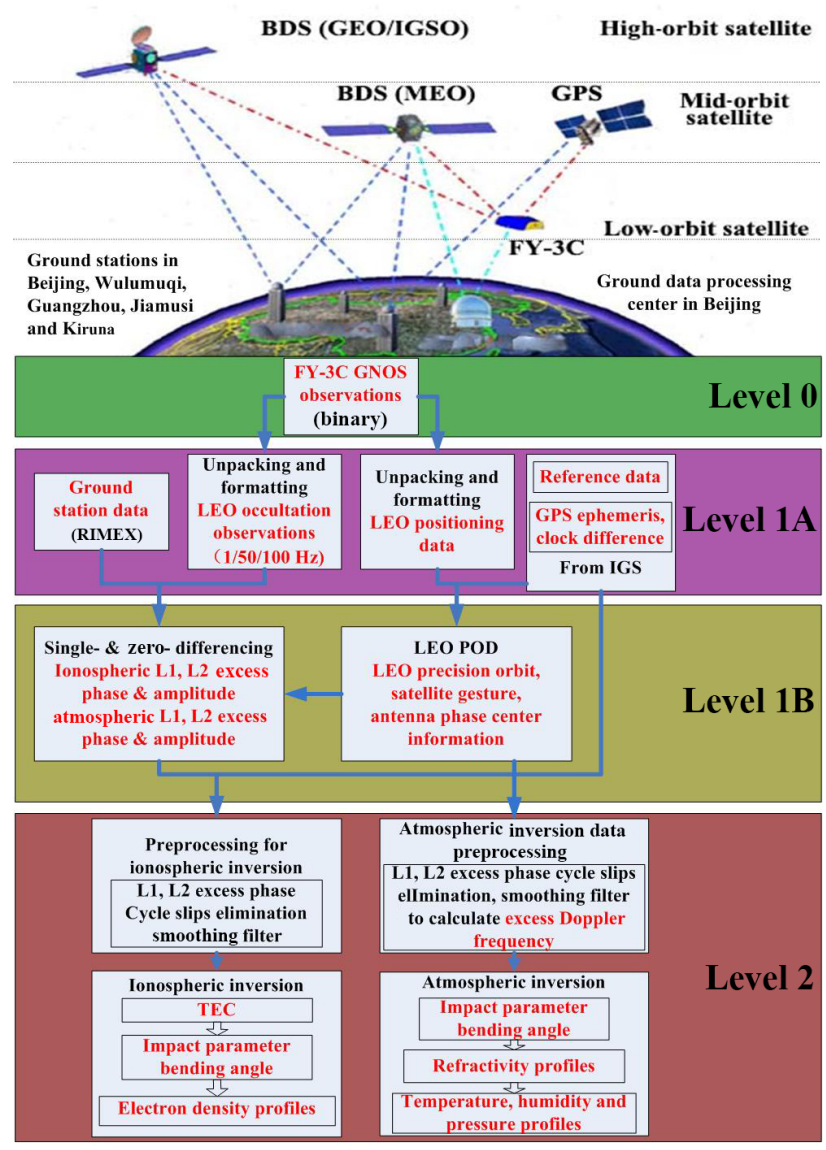

Figure 3. Overview diagram of the elements of the FY-3C GNOS mission and its data processing and data product levels, from raw data (Level 0) down to retrieved atmospheric and ionospheric profiles (Level 2).

almanac data, from the IGS website and other specific websites, for use by the LEO POD module.

Highly accurate measurements by the GNSS and LEO satellites in terms of time and position are the key to successful retrieval of the atmospheric and ionospheric profiles of an occultation event. According to the GNSS positioning package data and satellite precision ephemeris data, the POD program module conducts the LEO POD to obtain LEO satellite accurate position, velocity, satellite attitude, receiver clock error, and clock drift information. Based on the measurements of pseudo-range and carrier phase as well as the attitude information of the GNOS POD antenna, the GNSS clock offsets, GNSS precise orbit information, and the Earth orientation parameters, the LEO POD can be conducted by integrating the equations of celestial motion. Currently, in FY-3C GNOS data processing, the Bernese software (V5.0) (Dach et al., 2007) and the Position And Navigation Data Analyst (PANDA) software (Zhao et al., 2017) have been used and evaluated, and both of them can deliver highly accurate POD results.
Based on the LEO POD data and occultation observations, the excess-phase calculation program module is run to determine excess-phase data. Currently, in the processing of GNOS data, the single-differencing method is applied to obtain the excess phase as a function of time in an Earthcentered inertial reference frame, for all the GPS RO events and the BDS RO events which have sufficient reference satellites. Under the condition of fewer reference satellites, a zero-difference technique is applied and more appropriate for BDS RO events, since it does not require a reference satellite for simultaneous observations but requires an ultra-stable oscillator on an LEO receiver (Beyerle et al., 2005), which is available for GNOS (cf. Table 1; Bai et al., 2018). Based on the encouraging results of Bai et al. (2018), an in-depth comparison of the zero-differencing and single-differencing FY-3C GNOS RO data products has been started to evaluate whether the zero-differencing method can be used instead of the single-difference method in the operational data processing.

\subsection{FY-3C GNOS Level 2 data processing}

The data pre-processor module includes the atmospheric and ionospheric occultation data pre-processing modules, which mainly involve quality control, data filtering, and open-loop data quality control and initial processing.

The atmosphere inversion module includes the atmospheric impact parameter and bending angle calculation; inversion to refractivity; and temperature, pressure, and humidity retrieval. The Radio Occultation Processing Package (ROPP) software (V6.0) developed at the Radio Occultation Meteorology Satellite Application Facility (ROM SAF) is used for this purpose (Offiler, 2008; Culverwell et al., 2015). More specifically, from the excess phase the Doppler frequency can be obtained; then the bending angle as a function of impact parameter can be determined from the Doppler frequency shift and the corresponding satellite positions and velocities. Two distinct approaches have been used to determine bending angle profiles: above an altitude of $25 \mathrm{~km}$, where single-path rays propagate through the atmosphere, the geometric optics (GO) algorithm is used (Kursinski et al., 1997), while below $25 \mathrm{~km}$, where there can be multipath effects, the wave optics (WO) algorithm of Gorbunov et al. $(2004,2011)$ is used, also referred to as the canonical transform (CT2)) algorithm. In order to retrieve neutral atmospheric parameters, the ionosphere effects on the bending angles need to be eliminated. For the GNSS L band signals, the ionosphere refractivity is proportional to the inverse square of the frequencies, whereas the neutral atmosphere refractivity is almost independent of the frequencies (Vorob'ev and Krasil'nikova, 1994; Syndergaard et al., 2000). Therefore, a dual-frequency linear combination can mostly correct the first-order ionospheric effects (Vorob'ev and Krasil'nikova, 1994). However, there are some higher-order ionospheric effects that still remain in the bending angle profiles (Kursinski 
et al., 1997; Liu et al., 2013, 2015, 2016, 2018). To reduce the ionospheric residual errors and other small-scale noise, the statistical optimization technique is used together with the MSISE-90 climatology model. An optimal linear combination is expressed as a matrix equation to compute the neutral atmospheric bending angle and the ionospheric bending angle (Gorbunov, 2002).

After ionospheric correction, under the assumption of local spherical symmetry, the refractive index can be retrieved by an Abel transform from a given bending angle profile $\alpha$ as a function of impact parameter $a$, as shown in Eq. (1) (Fjeldbo et al., 1971; Melbourne et al., 1994; Kursinski et al., 1997), and then refractivity $N$ can be obtained from the refractive index $n$ as shown in Eq. (2):

$n\left(a_{0}\right)=\exp \left[-\frac{1}{\pi} \int_{a_{0}}^{\infty} \frac{\alpha(a)}{\sqrt{a^{2}-a_{0}^{2}}} \mathrm{~d} a\right]$,

$N=(n-1) \times 10^{6}$.

The refractivity is a function of temperature $(T)$, pressure $(p)$, water vapor pressure $(e)$, and electron density $\left(n_{\mathrm{e}}\right)$, as shown in Eq. (3).

$N=77.6 \frac{p}{T}+3.73 \times 10^{5} \frac{e}{T^{2}}-4.03 \times 10^{7} \frac{n_{\mathrm{e}}}{f^{2}}$,

where $f$ is the frequency of the GNSS signal. Therefore the refractivity profiles can be used to derive profiles of temperature, water vapor, and ionospheric electron density.

Because of the ambiguity of temperature and humidity in the lower troposphere (Healy and Eyre, 2000; Poli et al., 2002), one-dimensional variation (1-D-Var) analysis, involving collocated profiles of the Chinese global forecast model (used as background at T639L60 resolution), is used to retrieve temperature and humidity profiles (Liao et al., 2016b).

The ionosphere inversion module involves the ionospheric total electron content (TEC) calculation and the electron density retrieval, in which the dual-frequency difference method is used. The FY-3C GNOS ionospheric occultation data mainly include dual-frequency carrier phase and SNR observations, with a sampling rate of $1 \mathrm{~Hz}$. Since the primary mission of FY-3C GNOS is the neutral atmosphere occultation sounding, when there is no free channel, a new atmospheric occultation event will take over and occupy an ionospheric occultation channel. Therefore, the number of completed ionospheric occultation profiles is less than that of the atmospheric RO events, and there are typically around 220 GPS and 130 BDS ionospheric RO events per day.

When GNSS signals propagate through the ionosphere from GNSS satellites to the FY-3C satellite, their propagation paths are bent and delayed by ionosphere refraction effects. The TEC can hence be calculated by using the dual- frequency difference signal (e.g., Syndergaard et al., 2000),

$\mathrm{TEC}=\frac{f_{1}^{2} f_{2}^{2}}{C\left(f_{1}^{2}-f_{2}^{2}\right)}\left(L_{1}-L_{2}\right)$,

where $L_{1}$ and $L_{2}$ are the dual-frequency carrier phase observations, the constant $C=40.3082 \mathrm{~m}^{3} \mathrm{~s}^{-2}$, and $f_{1}$ and $f_{2}$ are the two signal frequencies. Then the electron density $N_{\mathrm{e}}$ in the ionosphere is derived by using an inverse Abel transformation,

$N_{\mathrm{e}}\left(a_{0}\right)=-\frac{1}{\pi} \int_{a_{0}}^{\text {LEO }} \frac{\mathrm{dTEC} / \mathrm{d} a}{\sqrt{a^{2}-a_{0}^{2}}} \mathrm{~d} a$,

where $N_{\mathrm{e}}$ is electron density and $a$ the impact parameter for ionospheric altitudes. We note that the orbit of the FY-3C satellite is at $833 \mathrm{~km}$ height, and our simulation estimation indicated that the ionosphere above the LEO satellite affects the accuracy of the retrieved results slightly, but the relative bias was less than $0.1 \%$. Therefore, the ionosphere above the LEO satellite can be neglected in the FY-3C GNOS situation. A simulation study (Wu et al., 2009) showed that the horizontal gradients could bring $\sim 6 \%$ to $\sim 10 \%$ root-mean-square error (RMSE), which is comparatively much higher.

\section{Preliminary validation and evaluation of the FY-3C GNOS data}

\subsection{Evaluation of the FY-3C satellite POD data}

The FY-3C GNOS observations and its POD results (e.g., clock estimates, position, and velocity) are fundamental and crucial elements of the whole GNOS RO data processing chain. Thus, the FY-3C satellite POD performance has been evaluated by difference GNSS data processing centers (Liao et al., 2016b; Li et al., 2017; Xiong et al., 2017; Zhao et al., 2017) by using the Bernese software (Liao et al., 2016b) and PANDA software (Zhao et al., 2017) separately. In all these POD data quality evaluations, an internal consistency metrics method named overlapping orbit differences (OODs) (Zhao et al., 2017) has been used.

The Li et al. (2017) study showed the overlapping orbit consistency, and the 3-D RMSE of OODs was found to be $2.7 \mathrm{~cm}$ by using GPS data only and $3.4 \mathrm{~cm}$ by using both GPS and BDS data together. Furthermore, the 3-D RMSE of OODs was found to be $30.1 \mathrm{~cm}$ by using all the BDS data and $8.4 \mathrm{~cm}$ by using the MEO and IGSO BDS data only. Similarly, the Xiong et al. (2017) study also showed overlapping orbit consistency, and the 3-D RMSE of OODs was found to be about $3.8 \mathrm{~cm}$ by using both GPS and BDS data together, and about $22 \mathrm{~cm}$ by using BDS data only.

Zhao et al. (2017) used the GPS and BDS observed data to conduct the POD of the FY-3C satellite. The solutions showed that the 3-D RMSE of $6 \mathrm{~h}$ OODs reached 2.3 and 


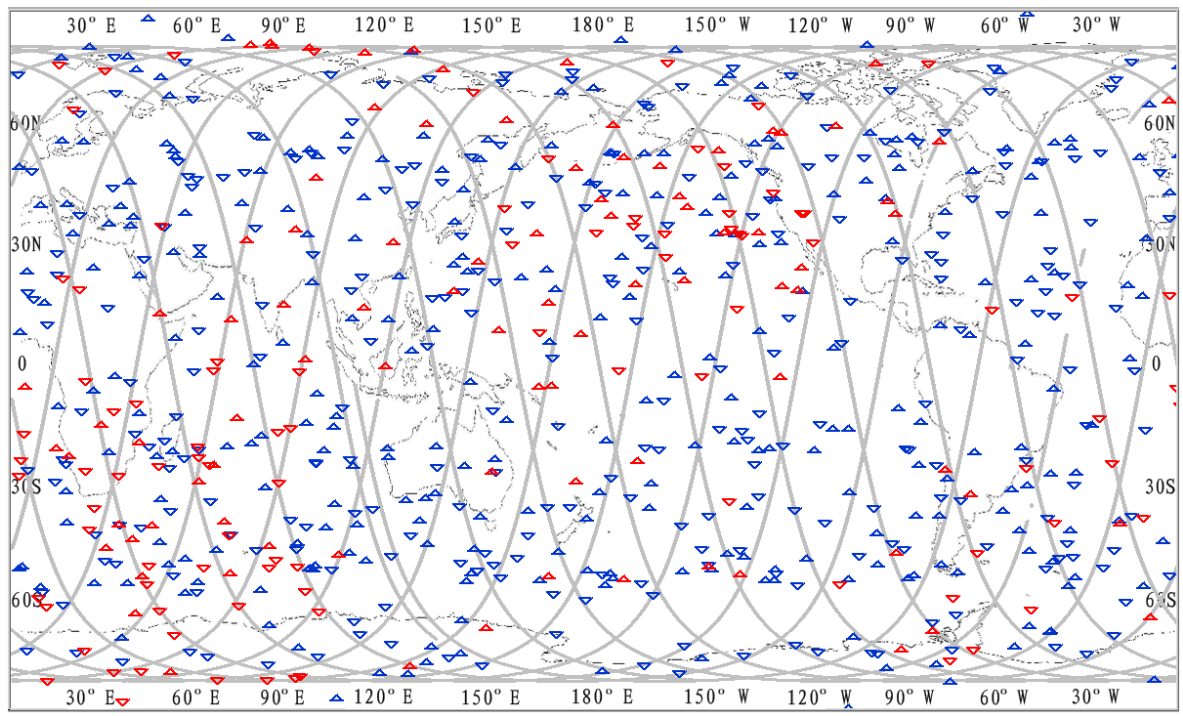

Figure 4. Distribution of the FY3 C-GNOS radio occultation events on 2 October 2013. There were 94 rising BDS RO events (upwardpointing red triangle), 90 setting BDS RO events (downward-pointing red triangle), 287 rising GPS RO events (upward-pointing blue triangle), and 256 setting GPS RO events (downward-pointing blue triangle) (source: Wang et al., 2015).

Table 2. The overall FY-3C POD performance.

\begin{tabular}{ll|l}
\hline Parameters & & Content \\
\hline Real-time navigation error (RMSE) & radial & $6.74 \mathrm{~m}$ \\
& tangential & $4.20 \mathrm{~m}$ \\
& normal & $3.00 \mathrm{~m}$ \\
\hline POD error (RMSE) & radial & $1.24 \mathrm{~cm}$ \\
& tangential & $1.60 \mathrm{~cm}$ \\
& normal & $3.07 \mathrm{~cm}$ \\
\hline Clock stability (1 s Allan deviation) & & $10^{-12}$
\end{tabular}

$15.8 \mathrm{~cm}$ for GPS-only and BDS-only procedures, respectively. The quality of the FY-3C POD result calculated by using the BDS data is worse than that calculated by using GPS data mainly because of the limited number of BDS satellites and the lower quality of BDS satellite POD data due to the small number of ground stations as well as restricted distribution of ground stations. In the same study, Zhao et al. (2017) improved the quality of BDS satellite POD data by using ground station data and accurate FY-3C POD data, which were retrieved from GPS observations.

At NSSC, both the Bernese and PANDA software have been used in the FY-3C satellite POD processing, and in this paragraph the POD performance of PANDA software is briefly discussed. Since the BDS is an incomplete constellation and can only provide regional navigation and positioning services, mainly in the Asia-Pacific area, the FY3C GNOS satellite POD processing is implemented by using the reduced-dynamic orbit determination method in which the zero-differencing algorithm with a least-squares estimator method and dual-frequency ionospheric correction has been conducted (Cai et al., 2017). The quality analysis of the FY-3C POD was conducted by using 2 months of data. The results showed that the mean RMSE of $6 \mathrm{~h}$ OODs along radial, tangential, and normal directions is $1.24,1.60$, and $3.07 \mathrm{~cm}$, respectively (Cai et al., 2017). The overall FY-3C POD performance - including velocity real-time position and velocity errors, POS position and velocity errors, and clock stability (100s Allan deviation) - is summarized in Table 2.

\subsection{Validation and evaluation of the FY3 C-GNOS atmospheric profiles}

After the launching of the FY-3C satellite, an in-orbit testing of the FY-3C GNOS data was presented by several papers (Wang et al., 2015; Liao et al., 2017; Bai et al., 2018).

In the Wang et al. (2015) study the GNOS RO events and their global distribution were analyzed; comparing with the GPS RO observations, the accuracy and consistency of BDS real-time positioning results and BDS RO products were analyzed. The preliminary results showed that, compared with the number of GPS GNOS RO events, the regional, incomplete BDS system with 14 navigation satellite can enhance the number of RO events by about $33 \%$ (Fig. 4). The statistical BDS and GPS GNOS RO data analyses, by using 17 pairs of BDS and GPS GNOS RO events in a week, showed that the BDS-GPS difference in standard deviation of refractivity, temperature, humidity, pressure, and ionospheric electron density is lower than $2 \%, 2 \mathrm{~K}, 1.5 \mathrm{~g} \mathrm{~kg}^{-1}, 2 \%$, and $15.6 \%$, respectively. Therefore, the BDS observations/products are 

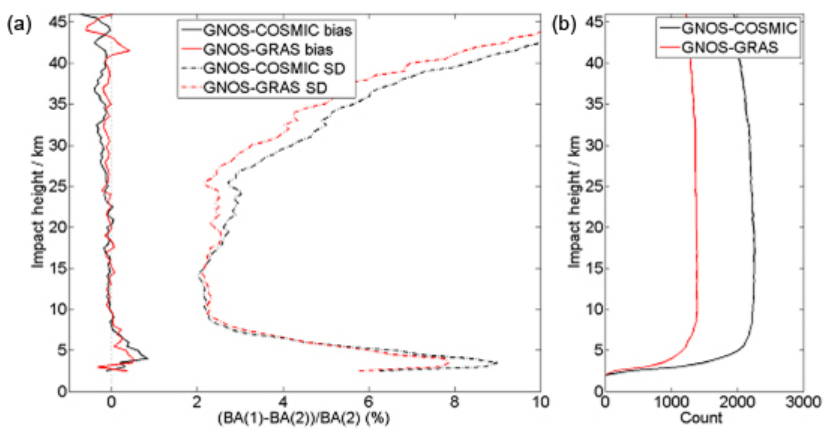

Figure 5. Comparisons of GNOS GPS, COSMIC, and MetOp/GRAS in terms of raw bending angles (from 1 November to 31 December 2013). In (a), the solid curves show the mean biases for the two collocation ensembles, and the dashed curves show the standard deviations. (b) shows the collocation ensemble size, increasing with altitude since less collocated profiles reach into the lower troposphere (source: Liao et al., 2016b).

in general consistent with those from GPS (Wang et al., 2015).

Taking COSMIC and MetOp/GRAS RO data as benchmarks, the GNOS GPS raw bending angles (i.e., bending angles after combining L1 and L2 frequencies but before the process of statistical optimization) were evaluated. The coincident $\mathrm{RO}$ events of the different missions are defined to collocate in time within $3 \mathrm{~h}$ and in distance within $200 \mathrm{~km}$ (Liao et al., 2016b). The distance is defined as the distance of tangent point locations of the collocated pair of occultations at a height of $30 \mathrm{~km}$ (this means that the distance of some point pairs in the RO profiles may be larger than $200 \mathrm{~km}$ ). For the period from 1 November to 31 December 2013, there were 17509 GNOS GPS, 32588 MetOp, and 22821 COSMIC occultations to build 1654 GNOS-MetOp coincident pairs and 2886 GNOS-COSMIC pairs. We did not yet include the data of GNOS BDS for which it could be expected that GPS and BDS show similar features, but it will be interesting and hence undertaken to probe the details of GPS and BDS differences in future work.

Figure 5 shows the mean and standard deviations of the bending angles in terms of percentage for the two collocation ensembles. The features of standard deviation changing with respect to altitude are similar to the mean bias. The best fit between GNOS, COSMIC, and MetOp, in terms of mean bias, occurs over the vertical range of $7-25 \mathrm{~km}$. Some relatively obvious positive and negative deviations exist below $7 \mathrm{~km}$ and above $25 \mathrm{~km}$, respectively, where the SNRs are lower. For detailed discussions, please refer to Liao et al. (2016b).

Taking the collocated European Centre for Medium-Range Weather Forecasts (ECMWF) analysis model data as reference ("true") values, the quality of atmospheric refractivity profiles from the FY-3C GNOS mission have been evaluated by Liao et al. (2016b). The results (Figs. 6 and 7) showed that
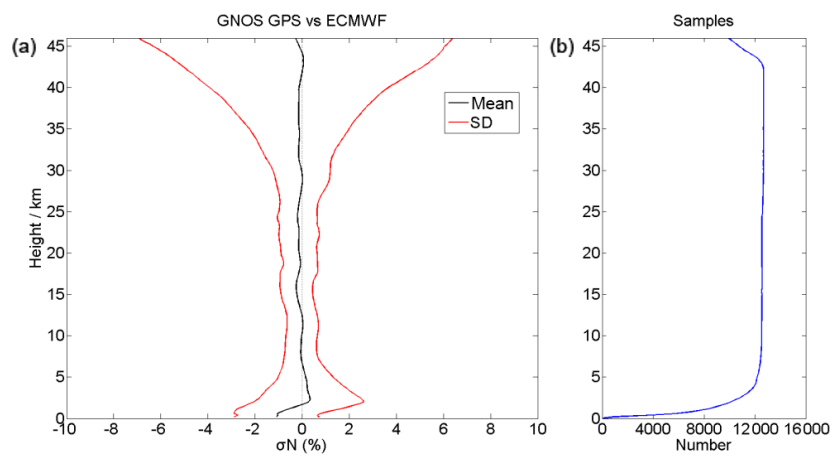

Figure 6. Refractivity deviation from the ECMWF analysis for FY3C GNOS GPS (from 1 November to 31 December 2013). The left panel shows the mean bias (black) and the standard deviation (red), and the right panel shows the samples used vs. altitude (source: Liao et al., 2016b).
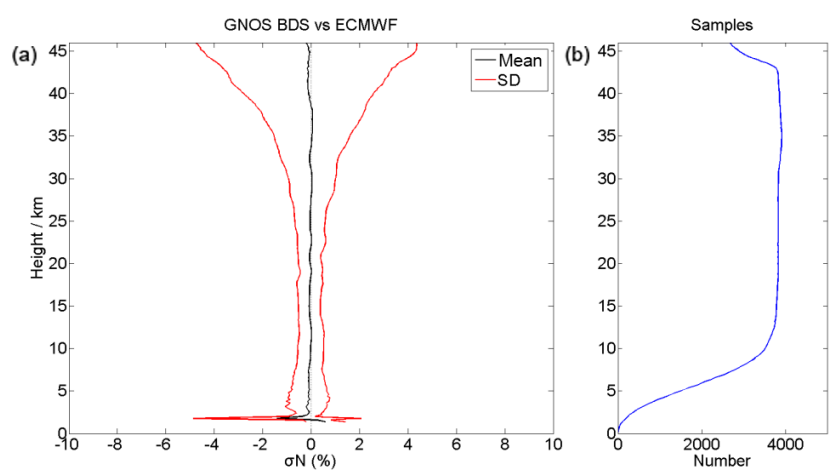

Figure 7. Refractivity deviation from the ECMWF analysis for FY3C GNOS BDS. The description is the same as for Fig. 6 (source: Liao et al., 2016b).

the mean bias of the refractivity obtained through GPS (BDS) GNOS was approximately $-0.09 \%(-0.04 \%)$ from the near surface to about $45 \mathrm{~km}$. While the average standard deviation was approximately $1.81 \%(1.26 \%)$, it was as low as $0.75 \%$ $(0.53 \%)$ in the range of $5-25 \mathrm{~km}$, where best sounding results are usually achieved.

Since FY-3C GNOS uses an ultra-stable oscillator with $1 \mathrm{~s}$ stability (Allan deviation) at the level of $10^{-12}$, both zerodifferencing and single-differencing excess-phase processing methods are basically feasible for FY-3C GNOS observations. Focusing on the evaluation of the bending angle and refractivity profiles that derived from zero-differencing and single-differencing excess-phase data of BDS RO, a comparison analysis has been conducted by using a 3 -month set of GNOS BDS RO data (October to December 2013) and the collocated profiles from ECMWF analyses (Bai et al., 2018). The statistics showed that the results from single and zero differencing are consistent in both bias and standard deviation, and also demonstrated the feasibility of zero differencing for GNOS BDS RO observations. The average bias (and standard deviation) of the bending angle and refractivity pro- 

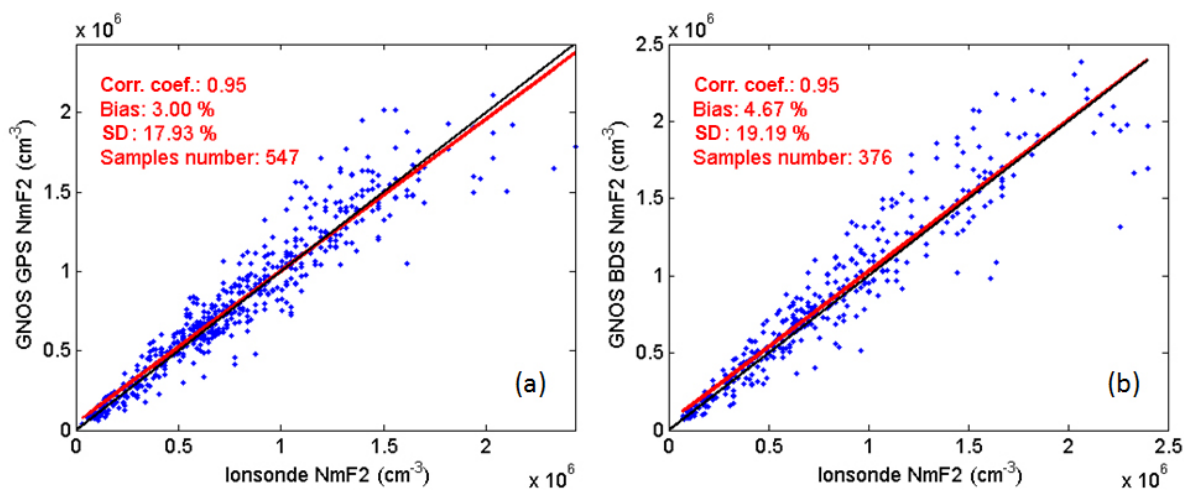

Figure 8. Comparison of NmF2 measurements from GNOS GPS (a) and BDS (b) occultation and ionosonde data. The linear regression of the absolute NmF2 values was computed using a standard difference technique, in which the black line is $y=x$, the red line is the fitted regression, corr. coef. is the correlation coefficient, bias is the statistical bias, and SD is the standard deviation (source: Bai et al., 2018).

files was found to be as small as about $0.05 \%$ to $0.2 \%$ (and $0.7 \%$ to $1.6 \%$ ) over the upper troposphere and lower stratosphere, including for the GEO, IGSO, and MEO subsets (Bai et al., 2018).

\subsection{Validation and evaluation of the FY3 C-GNOS ionospheric profiles}

We evaluated the FY-3C GNOS ionosphere electron density profiles through a statistical comparison analysis with ionosonde data, in which both the BDS and GPS GNOS RO data were compared against observations from 69 ionosonde stations. For detailed information of FY-3C GNOS ionosphere occultation data processing, and the evaluation analysis algorithms, we refer to Yang et al. (2017). Relevant statistical results are shown in Fig. 8 and Table 3. The linear regression of absolute maximum electron density in F2 layer $(\mathrm{NmF} 2)$ values derived from the GNOS GPS occultation and ionosonde data gives a correlation coefficient of 0.95 , statistical bias of $3.0 \%$, and standard deviation of $17.9 \%$, in which a total of 547 matching pairs of data were used. Similarly, the linear regression of absolute $\mathrm{NmF} 2$ values derived from the GNOS BDS occultation and ionosonde data gives a correlation coefficient of the fitted regression of 0.95 , statistical bias of $4.7 \%$, and standard deviation of $19.2 \%$, in which a total of 376 matching pairs of data were used. One can see that the bias and standard deviation of the NmF2 derived from the GNOS BDS occultation and GPS occultation are consistent and comparable (Yang et al., 2017). The statistics of GNOS NmF2 are also in line with the CHAMP mission, whose $\mathrm{NmF} 2$ average bias is $-1.7 \%$ and standard deviation is $17.8 \%$ (Jakowski et al., 2002).
Table 3. The statistics of the GNOS GPS and BDS RO NmF2 index.

\begin{tabular}{ll}
\hline Parameters & Content \\
\hline GPS Nmf2 bias & $3.00 \%$ \\
GPS Nmf2 SD & $17.93 \%$ \\
BDS Nmf2 bias & $4.67 \%$ \\
BDS Nmf2 SD & $19.19 \%$ \\
\hline
\end{tabular}

\section{Applications of FY-3C GNOS data products}

\subsection{Applications of the atmospheric products}

The FY-3C GNOS data, mainly including bending angle and refractivity profiles, have been assimilated in the Global/Regional Assimilation and Prediction System (GRAPES) of the China Meteorological Administration (CMA; Liu et al., 2014) for the NWP application. Figure 9 shows the effects of the GPS GNOS RO data only (red line) and both the BDS and GPS GNOS RO data (blue line), used in 7-day forecast at $500 \mathrm{hPa}$ altitude level, on the NWP results, in which the black line denotes the reference line, and the $x$ axis and $y$ axis denote the forecast time range and the anomaly correlation coefficient (ACC), respectively. The ACC can be regarded as a skill score relative to the climate knowledge and is positively orientated, with increasing ACC values indicating increasing "success". The results indicated that FY-3C GNOS RO data have a positive effect on analysis and forecast in all medium-term forecast ranges in GRAPES, not only in the Southern Hemisphere, where conventional observations are lacking, but also in the Northern Hemisphere, where data are more dense.

Figure 10 shows an evaluation score card of the effects of the FY-3C GNOS RO data on the GRAPES forecast results, in which the grey color denotes that the effect is tiny, the red color denotes positive effect, and the green color denotes negative effect. The evaluation results showed, that except for 

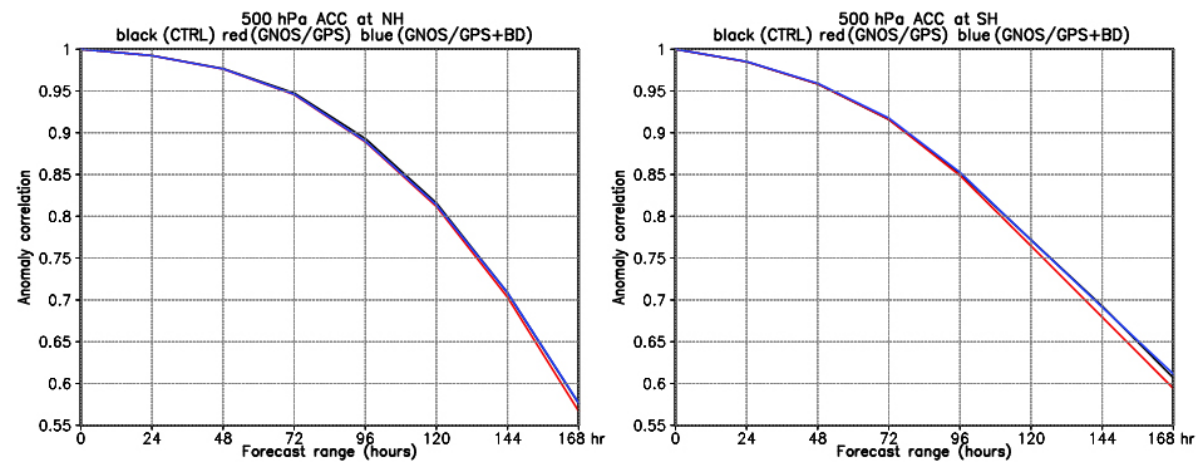

Figure 9. Comparison of the anomaly correlation coefficients of the without-GNOS-RO-data reference case (black line) and the other cases, assimilated GPS GNOS RO data only (red line), and assimilated GPS and BDS GNOS RO data (blue line). The left and right panels show the results of the Northern and Southern Hemisphere, respectively.

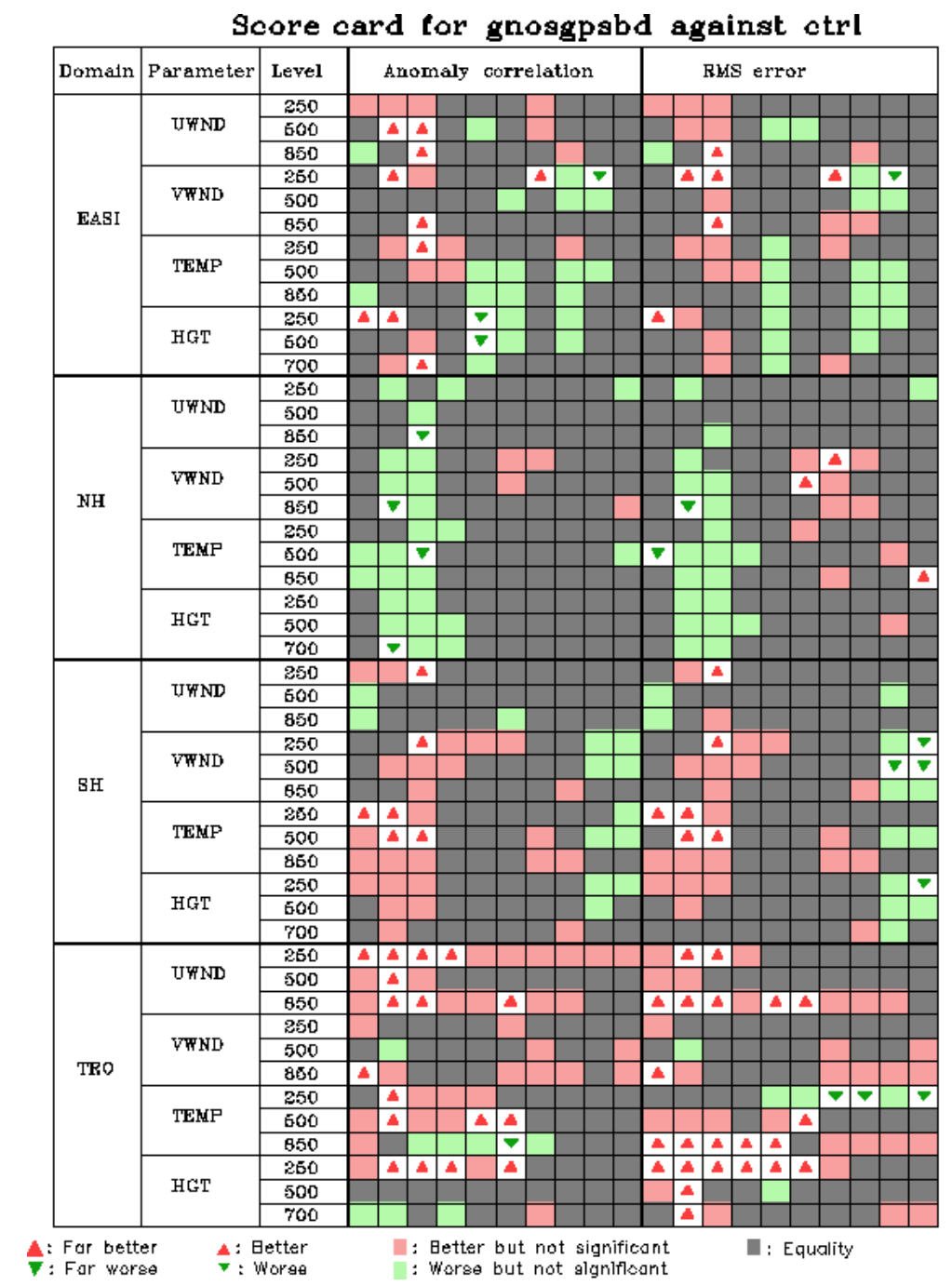

Figure 10. Evaluation score card of GPS and BDS FY-3C GNOS RO data assimilation effects on the GRAPES forecast model. 
somewhere in the Northern Hemisphere and East Asia, the GPS and BDS GNOS data tend to have overall clearly positive effects on the GRAPES NWP results. Since June 2017, the GNOS RO data are therefore operationally assimilated into GRAPES by the CMA.

\subsection{Applications of the FY3 C-GNOS ionospheric products}

The FY-3C GNOS ionospheric products have been applied in the ionospheric and space weather research areas. A comparison has been made between ionospheric peak parameters retrieved by FY-3C GNOS RO data and those measured by globally distributed ionosondes (Mao et al., 2016). Reasonable agreement was obtained in this case; the results indicated that $\mathrm{NmF} 2$ and hmF2 (the height of the F2 maximum) retrieved from FY-3C GNOS measurements are reliable and can be used for ionospheric physics studies. The comparison between the FY-3C GNOS data and the International Reference Ionosphere (IRI) model is also reasonably good, but the IRI model tends to overestimate $\mathrm{NmF} 2$ at the crests of the equatorial anomalies (Mao et al., 2016). In addition, Yang et al. (2017) analyzed sporadic E-layer events, caused by precipitating particle in the auroral region, by using FY-3C GNOS observations. The results showed that the disturbance intensity of the sporadic E layers in the summer hemisphere is significantly greater than that in the same latitude region in the winter hemisphere. Additionally, the occurrence rate of sporadic E layers in the summer hemisphere was found to be significantly higher than that in the winter hemisphere.

Based on the validated FY-3C GNOS ionospheric data and ionosonde stations observations, the global ionospheric effects of the strong magnetic storm event in March 2015 were analyzed by Bai et al. (2016). Both the analyses of GNOS ionospheric data and ionosonde station observations showed that the magnetic storm caused a significant disturbance in $\mathrm{NmF} 2$ and hmF2 levels, and the average NmF2 featured the same basic trends in the zone of geomagnetic inclination between 40 and $80^{\circ}$. Suppressed daytime and nighttime NmF2 levels indicated mainly negative storm conditions (Fig. 11). The analysis in this way also demonstrated the value of the FY-3C GNOS data and especially confirmed the utility of its ionosphere products for statistical and event-specific ionospheric physics analyses.

\section{Summary and conclusions}

FY-3C GNOS is the first BDS- and GPS-capable GNSS RO sounder in space and combines a state-of-the-art RO receiver, which has meanwhile been successfully running in orbit for more than 4 years. So far, a large data set of FY-3C GNOS RO observations has been obtained, which includes both atmospheric and ionospheric RO products. These products have been validated and evaluated by difference institutions,

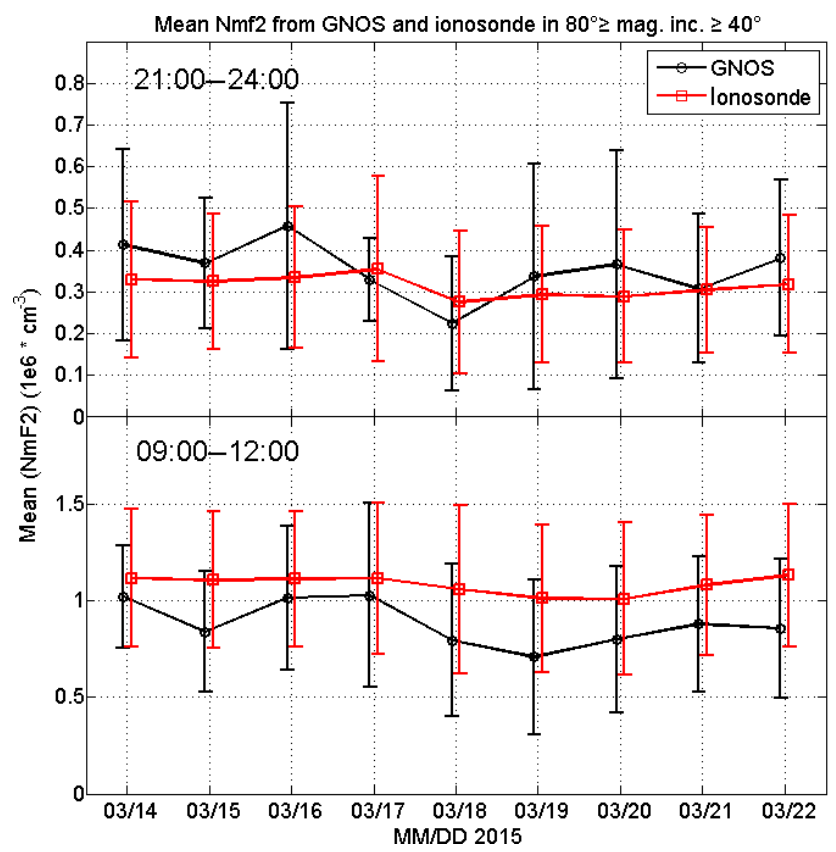

Figure 11. Comparison of average $\mathrm{NmF} 2$ values from 17 ionosonde stations and GNOS ionosphere data in the region of magnetic inclinations between 40 and $80^{\circ}$ in the Northern Hemisphere (source: Bai et al., 2016).

and the results showed that FY-3C satellite POD accuracy reaches centimeter level.

Regarding the GNOS atmospheric data, compared with collocated ECMWF analysis data, the mean bias (standard deviation) of the atmospheric refractivity is less than $1 \%$ $(2 \%)$ in the upper troposphere and lower stratosphere. When the GNOS ionospheric data are compared with ionosonde station data, the statistical bias (standard deviation) of both the BDS and GPS GNOS ionospheric electron density NmF2 values is less than $5 \%(20 \%)$. The consistency of BDS and GPS RO products has been successfully validated as well; it has proven the utility of the GNOS RO data for applications in numerical weather prediction (NWP), global climate monitoring (GCM), and space weather research (SWR).

So far the GNOS RO data products have been widely used in NWP and SWR applications in China mainly. In the near future, the GNOS RO data will also be heavily used for GCM applications, through cooperation research between NSSC (Beijing, China) and WEGC (Graz, Austria). Wider international use in NWP and other applications will also follow based on the continuously improving data product quality of the GNOS data.

With the further expansion of the GNSS transmitter satellite constellations, and the additional GNOS instruments launched on board the FY-3 series of satellites, the FY-3 GNOS observations are expected to provide an essential future contribution to the pool of international high-quality at- 
mospheric and ionospheric RO products, for substantial benefit of NWP, GCM, and SWR.

Data availability. The ECMWF (Reading, UK) provides access to their archived analysis and forecast data, available at http://www. ecmwf.int/en/forecasts/datasets (last access: 23 August 2018), and NOAA-NCEI (Boulder, CO, USA) provides access to their Integrated Global Radiosonde Archive (IGRA), available at http:// www.ncdc.noaa.gov/data-access/weather-balloon-data (last access: 23 August 2018). GNOS-related data on the results of this study are currently not in the public domain and therefore cannot be accessed online; in case of specific interests, data requests can be sent to the corresponding authors.

Competing interests. The authors declare that they have no conflict of interest.

Acknowledgements. This research was supported by the National Natural Science Foundation of China (grant nos. 41775034, 41405039, 41405040, 41505030, and 41606206), the Strategic Priority Research Program of the Chinese Academy of Sciences (grant no. XDA15012300), the Scientific Research Project of the Chinese Academy of Sciences (grant no. YZ201129), and the FengYun 3 (FY-3) Global Navigation Satellite System Occultation Sounder (GNOS) development and manufacture project led by NSSC/CAS. The research at WEGC was supported by the Austrian Aeronautics and Space Agency of the Austrian Research Promotion Agency (FFG-ALR) under projects OPSCLIMVALUE (grant no. 848013) and EOPCLIMTRACK (grant no. 859773).

Edited by: Joanna Joiner

Reviewed by: three anonymous referees

\section{References}

Anthes, R. A.: Exploring Earth's atmosphere with radio occultation: contributions to weather, climate and space weather, Atmos. Meas. Tech., 4, 1077-1103, https://doi.org/10.5194/amt-4-10772011, 2011.

Anthes, R. A., Rocken, C., and Kuo, Y.-H.: Applications of COSMIC to meteorology and climate, Terr. Atmos. Ocean. Sci., 11, 115-156, 2000.

Anthes, R. A., Bernhardt, P. A., Chen, Y., Cucurull, L., Dymond, K. F., Ector, D., Healy, S. B., Ho, S.-P., Hunt, D. C., Kuo, Y.-H., Liu, H., Manning, K., McCormick, C., Meehan, T. K., Randel, W. J., Rocken, C., Schreiner, W. S., Sokolovskiy, S. V., Syndergaard, S., Thompson, D. C., Trenberth, K. E., Wee, T.-K., Yen, N. L., and Zeng, Z.: The COSMIC/FORMOSAT3 mission: Early results, B. Am. Meteorol. Soc., 89, 313-333, https://doi.org/10.1175/BAMS-89-3-313, 2008.

Ao, C. O., Hajj, G. A., Meehan, T. K., Dong, D., Iijima, B. A., Mannucci, J. A., and Kursinski, E. R.: Rising and setting GPS occultations by use of open-loop tracking, J. Geophys. Res., 114, D04101, https://doi.org/10.1029/2008JD010483, 2009.
Aparicio, J. and Deblonde, G.: Impact of the assimilation of CHAMP refractivity profiles in Environment Canada global forecasts, Mon. Weather Rev., 136, 257-275, 2008.

Arras, C., Wickert, J., Beyerle, G., Heise, S., Schmidt, T., and Jacobi, C.: A global climatology of ionospheric irregularities derived from GPS radio occultation, Geophys. Res. Lett., 35, 137149, https://doi.org/10.1029/2008gl034158, 2008.

Bai, W. H., Sun, Y. Q., Du, Q. F., and Wang, X. Y.: FY3 - GNOS Instrument Performance and Results Analysis in Mountain-based Validation Experiment, COSPAR 2012, India, 2012.

Bai, W. H., Sun, Y. Q., Du, Q. F., Yang, G. L., Yang, Z. D., Zhang, P., Bi, Y. M., Wang, X. Y., Cheng, C., and Han, Y.: An introduction to the FY3 GNOS instrument and mountain-top tests, Atmos. Meas. Tech., 7, 1817-1823, https://doi.org/10.5194/amt7-1817-2014, 2014a.

Bai, W. H., Sun, Y. Q., Du, Q. F., Yang, G. 1., Yang, Z. D., Zhang, P., Bi, Y. M., Wang, X. Y., Wang, D. W., and Meng, X. G.: An introduction to FY3 GNOS in-orbit performance and preliminary validation results, EGU General Assembly, Vienna, Geophysical Research Abstracts, 16, EGU2014-4036, 2014b.

Bai, W., Wang, G., Sun, Y., Shi, J., Meng, X., Wang, D., Du, Q., Wang, X., Xia, J., Cai, Y., Liu, C., Li, W., Wu, C., Zhao, D., Wu, D., and Liu, C.: Application of Fengyun 3-C GNSS occulation sounder for assessing global ionospheric response to magnetic storm event, Atmos. Meas. Tech. Discuss., https://doi.org/10.5194/amt-2016-291, in review, 2016.

Bai, W., Liu, C., Meng, X., Sun, Y., Kirchengast, G., Du, Q., Wang, X., Yang, G., Liao, M., Yang, Z., Zhao, D., Xia, J., Cai, Y., Liu, L., and Wang, D.: Evaluation of atmospheric profiles derived from single- and zero-difference excess phase processing of BeiDou radio occultation data from the FY-3C GNOS mission, Atmos. Meas. Tech., 11, 819-833, https://doi.org/10.5194/amt-11819-2018, 2018.

Beyerle, G., Schmidt, T., Michalak, G., Heise, S., Wickert, J., and Reigber, C.: GPS radio occultation with GRACE: Atmospheric profiling utilizing the zero difference technique, Geophys. Res. Lett., 32, L13806, https://doi.org/10.1029/2005GL023109, 2005.

Brahmanandam, P. S., Uma, G., Liu, J. Y., Chu, Y. H., Latha Devi, N. S. M. P., and Kakinami, Y.: Global S4 index variations observed using FORMOSAT-3/COSMIC GPS RO technique during a solar minimum year, J. Geophys. Res.-Space Physics, 117, A09322, https://doi.org/10.1029/2012ja017966, 2012.

Cai, Y., Bai, W., Wang, X., Sun, Y., Du, Q., Zhao, D., Meng, X., Liu, C., Xia, J., Wang, D., Wu, D., Li, W., Wu, C., and Liu, C.: In-orbit performance of GNOS on-board FY3-C and the enhancements for FY3-D satellite, Adv. Space Res., 60, 28122821, https://doi.org/10.1016/j.asr.2017.05.001, 2017.

Cucurull, L. and Derber, J. C.: Operational implementation of COSMIC observations into NCEP's global data assimilation system, Weather Forecast., 23, 702-711, https://doi.org/10.1175/2008WAF2007070.1, 2008.

Culverwell, I. D., Lewis, H. W., Offiler, D., Marquardt, C., and Burrows, C. P.: The Radio Occultation Processing Package, ROPP, Atmos. Meas. Tech., 8, 1887-1899, https://doi.org/10.5194/amt8-1887-2015, 2015.

Dach, R., Hugentobler, U., Fridez, P., and Meindl, M.: Bernese GPS Software Version 5.0. Astronomical Institute, University of Bern, Switzerland, 2007. 
Du, Q. F., Sun, Y. Q., Bai, W. H., Wang, X. Y., Wang, D. W., Meng, X. G., Cai, Y. R., Liu, C. L., Wu, D., Wu, C. J., Li, W., Xia, J. M., and Liu, C.: The Next Generation GNOS Instrument For FY3 Meteorological Satellites, IGARSS 2016, Beijing, 381-383, 2016.

Edwards, P. G. and Pawlak, D.: Metop: The space segment for Eumetsat's Polar System, ESA Bulletin, 102, 6-18, 2000.

Fjeldbo, G., Kliore, G. A., and Eshleman, V. R.: The neutral atmosphere of Venus as studied with the Mariner V radio occultation experiments, Astron. J., 76, 123-140, 1971.

Foelsche, U., Pirscher, B., Borsche, M., Kirchengast, G., and Wickert, J.: Assessing the climate monitoring utility of radio occultation data: From CHAMP to FORMOSAT3/COSMIC, Terr. Atmos. Ocean. Sci., 20, 155-170, https://doi.org/10.3319/TAO.2008.01.14.01(F3C), 2009.

Foelsche, U., Scherllin-Pirscher, B., Ladstädter, F., Steiner, A. K., and Kirchengast, G.: Refractivity and temperature climate records from multiple radio occultation satellites consistent within 0.05\%, Atmos. Meas. Tech., 4, 2007-2018, https://doi.org/10.5194/amt-4-2007-2011, 2011.

Gorbunov, M. E.: Ionospheric correction and statistical optimization of radio occultation data, Radio Sci., 37, 1084, https://doi.org/10.1029/2000RS002370, 2002.

Gorbunov, M. E. and Lauritsen, K. B.: Analysis of wave fields by Fourier integral operators and their application for radio occultations, Radio Sci., 39, RS4010, https://doi.org/10.1029/2003RS002971, 2004.

Gorbunov, M. E., Gurvich, A. S., and Bengtsson, L.: Advanced algorithms of inversion of GPS/MET satellite data and their application to reconstruction of temperature and humidity, Tech. Rep. 211, Max Planck Inst. for Meteorol., Hamburg, Germany, 1996.

Gorbunov, M. E., Lauritsen, K. B., Benzon, H.-H., Larsen, G. B., Syndergaard, S., and Sørensen, M. B.: Processing of GRAS/METOP radio occultation data recorded in closed-loop and raw-sampling modes, Atmos. Meas. Tech., 4, 1021-1026, https://doi.org/10.5194/amt-4-1021-2011, 2011.

Harnisch, F., Healy, S. B., Bauer, P., and English, S. J.: Scaling of GNSS radio occultation impact with observation number using an ensemble of data assimilations, Mon. Weather Rev., 141, 4395-4413, https://doi.org/10.1175/MWR-D-13-00098.1, 2013.

Healy, S. and Eyre, J. R.: Retrieving temperature, water vapor and surface pressure information from refractive index profiles derived by radio occultation: A simulation study, Q. J. Roy. Meteorol. Soc., 126, 1661-1683, 2000.

Healy, S. B. and Thépaut, J.-N.: Assimilation experiments with CHAMP GPS radio occultation measurements, Q. J. Roy. Meteorol. Soc., 132, 605-623, 2006.

Ho, S.-P., Kirchengast, G., Leroy, S., Wickert, J., Mannucci, A. J., Steiner, A. K., Hunt, D., Schreiner, W., Sokolovskiy, S., Ao, C., Borsche, M., von Engeln, A., Foelsche, U., Heise, S., Iijima, B., Kuo, Y.-H., Kursinski, R., Pirscher, B., Ringer, M., Rocken, C., and Schmidt, T.: Estimating the uncertainty of using GPS radio occultation data for climate monitoring: Intercomparison of CHAMP refractivity climate records from 2002 to 2006 from different data centers, J. Geophys. Res., 114, D23107, https://doi.org/10.1029/2009JD011969, 2009.

Ho, S.-P., Hunt, D., Steiner, A. K., Mannucci, A. J., Kirchengast, G., Gleisner, H., Heise, S., von Engeln, A., Marquardt, C., Sokolovskiy, S., Schreiner, W., Scherllin-Pirscher,
B., Ao, C., Wickert, J., Syndergaard, S., Lauritsen, K. B., Leroy, S., Kursinski, E. R., Kuo, Y-H., Foelsche, U., Schmidt, T., and Gorbunov, M.: Reproducibility of GPS radio occultation data for climate monitoring: Profile-to-profile inter-comparison of CHAMP climate records 2002 to 2008 from six data centers, J. Geophys. Res., 117, D18111, https://doi.org/10.1029/2012JD017665, 2012.

Huang, C.-Y., Kuo, Y.-H., Chen, S.-Y., Terng, C.-T., and Chien, F.-C., Lin, P.-L., Kueh, M.-T., Chen, S.-H., Yang, M.-J., Wang, C.-J., and Prasad Rao, A. S. K. A. V.: Impact of GPS radio occultation data assimilation on regional weather predictions, GPS Solut., 14, 35-49, https://doi.org/10.1007/s10291-009-0144-1, 2010.

Jakowski, N., Wehrenpfennig, A., Heise, S., Reigber, C., Lühr, H., Grunwaldt, L., and Meehan, T. K.: GPS radio occultation measurements of the ionosphere from CHAMP: Early results, Geophys. Res. Lett., 29, 1457, https://doi.org/10.1029/2001GL014364, 2002.

Kuo, Y.-H., Zou, X., Chen, S. J., Huang, W., and Guo, Y.-R., Anthes, R. A., Exner, M., Hunt, D., Rocken, C., and Sokolovskiy, S.: A GPS/MET sonding through an intense upper-level front, B. Am. Meteorol. Soc., 79, 617-626, 1998.

Kursinski, E. R., Hajj, G. A., Bertiger, W. I., Leroy, S. S., Meehan, T. K., Romans, L. J., Schofield, J. T., McCleese, D. J., Melbourne, W. G., Thornton, C. L., Yunck, T. P., Eyre, J. R., and Nagatani, R. N.: Initial Results of radio occultation observations of Earth's atmosphere using the Global Positioning System, Science, 271, 1107-1110, 1996.

Kursinski, E. R., Hajj, G. A., Hardy, K. R., Schofield, J. T., and Linfield, R.: Observing Earth's atmosphere with radio occultation measurements, J. Geophys. Res., 102, 23429-23465, 1997.

Lackner, B. C., Steiner, A. K., Hegerl, G. C., and Kirchengast, G.: Atmospheric climate change detection by radio occultation data using a fingerprinting method, J. Climate, 24, 5275-5291, https://doi.org/10.1175/2011JCLI3966.1, 2011.

Le Marshall, J., Xiao, Y., Norman, R., Zhang, K., Rea, A., Cucurull, L., Seecamp, R., Steinle, P., Puri, K., and Le, T.: The beneficial impact of radio occultation observations on Australian region forecasts, Australian Meteorol. Oceanogr. J., 60, 121-125, 2010.

Leroy, S. S.: The measurement of geopotential heights by GPS radio occultation, J. Geophys. Res., 102, 6971-6986, 1997.

Li, M., Li, W., Shi, C., Jiang, K., Guo, X., Dai, X., Meng, X., Yang, Z., Yang, G., and Liao, M.: Precise orbit determination of the Fengyun-3C satellite using onboard GPS and BDS observations, J. Geodesy, 91, 1313-1327, 2017.

Liao, M., Zhang, P., Bi, Y. M., and Yang, G. L.: A preliminary estimation of the radio occultation products accuracy from the Fengyun-3C meteorological satellite, Acta Meteorol. Sin., 73, 1131-1140, 2015.

Liao, M., Zhang, P., Yang, G. 1., Bai, W. H., Meng, X. G., Du, Q. F., and Sun, Y. Q.: Status of Radio Occultation Sounding Technology of FY-3C GNOS, Adv. Meteorol. Sci. Technol., 6, 83-87, 2016a.

Liao, M., Zhang, P., Yang, G.-L., Bi, Y.-M., Liu, Y., Bai, W.H., Meng, X.-G., Du, Q.-F., and Sun, Y.-Q.: Preliminary validation of the refractivity from the new radio occultation sounder GNOS/FY-3C, Atmos. Meas. Tech., 9, 781-792, https://doi.org/10.5194/amt-9-781-2016, 2016b. 
Liu, C. L., Kirchengast, G., Zhang, K. F., Norman, R., Li, Y., Zhang, S. C., Carter, B., Fritzer, J., Schwaerz, M., Choy, S. L., Wu, S. Q., and Tan, Z. X.: Characterisation of residual ionospheric errors in bending angles using GNSS RO end-to-end simulations, Adv. Space Res., 52, 821-836, https://doi.org/10.1016/j.asr.2013.05.021, 2013.

Liu, C. L., Kirchengast, G., Zhang, K. F., Tan, Z. X., Johannes, F., and Sun, Y. Q.: The effects of residual ionospheric errors on GPS radio occultation temperature, Chinese J. Geophys., 57, 24042414, 2014 (in Chinese).

Liu, C. L., Kirchengast, G., Zhang, K., Norman, R., Li, Y., Zhang, S. C., Fritzer, J., Schwaerz, M., Wu, S. Q., and Tan, Z. X.: Quantifying residual ionospheric errors in GNSS radio occultation bending angles based on ensembles of profiles from end-to-end simulations, Atmos. Meas. Tech., 8, 2999-3019, https://doi.org/10.5194/amt-8-2999-2015, 2015.

Liu, C., Kirchengast, G., Sun, Y., Bai, W., Du, Q., Wang, X., Meng, X., Wang, D., Cai, Y., Wu, D., Wu, C., Li, W., Xia, J., and Liu, C.: Study of bending angle residual ionosphric error in real RO data, 2016 IEEE International Geoscience and Remote Sensing Symposium (IGARSS), 41714174, https://doi.org/10.1109/igarss.2016.7730087, 2016.

Liu, C., Kirchengast, G., Sun, Y., Zhang, K., Norman, R., Schwaerz, M., Bai, W., Du, Q., and Li, Y.: Analysis of ionospheric structure influences on residual ionospheric errors in GNSS radio occultation bending angles based on ray tracing simulations, Atmos. Meas. Tech., 11, 2427-2440, https://doi.org/10.5194/amt11-2427-2018, 2018.

Liu, Y. and Xue, J.: Assimilation of GNSS radio occultation observations in GRAPES, Atmos. Meas. Tech., 7, 3935-3946, https://doi.org/10.5194/amt-7-3935-2014, 2014.

Loescher, A. and Kirchengast, G.: Variational data assimilation for deriving global climate analyses from GNSS radio occultation data, GPS Solut., 12, 227-235, https://doi.org/10.1007/s10291008-0087-y, 2008.

Loiselet, M., Stricker, N., Menard, Y., and Luntama, J.-P.: GRAS - Metop's GPS-based atmospheric sounder, ESA Bulletin, 102, 38-44, 2000.

Luntama, J.-P., Kirchengast, G., Borsche, M., Foelsche, U., Steiner, A., Healy, S., von Engeln, A., O'Clerigh, E., and Marquardt, C.: Prospects of the EPS GRAS mission for operational atmospheric applications, B. Am. Meteorol. Soc., 89, 1863-1875, https://doi.org/10.1175/2008BAMS2399.1, 2008.

Mao, T., Sun, L., Yang, G., Yue, X., Yu, T., Huang, C., Zeng, Z., Wang, Y., and Wang, J.: First Ionospheric Radio-Occultation Measurements From GNSS Occultation Sounder on the Chinese Feng-Yun 3C Satellite, IEEE T. Geosci. Remote, 54, 5044-5053, 2016.

Melbourne, W. G., Davis, E. S., Duncan, C. B., Hajj, G. A., Hardy, K. R., Kursinski, E. R., Meehan, T. K., Yong, L. E., and Yunck, T. P.: The application of spaceborne GPS to atmospheric limb sounding and global change monitoring, JPL Publ. 94-18, Jet Propulsion Lab, Calif. Inst. of Technol., Pasadena, CA, 1994.

Offiler, D.: The radio occultation processing package (ROPP) an overview, Tech. Rep., GRAS SAF, Document-No: SAF/GRAS/METO/UG/ROPP/001, 2008.

Pi, X., Mannucci, A. J., Lindqwister, U. J., and Ho, C. M.: Monitoring of global ionospheric irregularities using the World- wide GPS Network, Geophys. Res. Lett., 24, 2283-2286, https://doi.org/10.1029/97g102273, 1997.

Poli, P., Joiner, J., and Kursinski, E. R.: 1DVAR analysis of temperature and humidity using GPS radio occultation refractivity data, J. Geophys. Res., 107, 4448, https://doi.org/10.1029/2001JD000935, 2002.

Poli, P., Healy, S. B., Rabier, F., and Pailleux, J.: Preliminary assessment of the scalability of GPS radio occultations impact in numerical weather prediction, Geophys. Res. Lett., 35, L23811, https://doi.org/10.1029/2008GL035873, 2008.

Rocken, C., Anthes, R., Exner, M., Hunt, D., Sokolovskiy, S., Ware, R., Gorbunov, M., Schreiner, W., Feng, D., Herman, B., Kuo, Y.H., and Zou, X.: Analysis and validation of GPS/MET data in the neutral atmosphere, J. Geophys. Res., 102, 29849-29866, 1997.

Rocken, C., Kuo, Y.-H., Schreiner, W., Hunt, D. C., and Sokolovskiy, S. V.: COSMIC system description, Special Issue, Terr. Atmos. Ocean. Sci., 11, 21-52, 2000.

Schmidt, T., Heise, S., Wickert, J., Beyerle, G., and Reigber, C.: GPS radio occultation with CHAMP and SAC-C: global monitoring of thermal tropopause parameters, Atmos. Chem. Phys., 5, 1473-1488, https://doi.org/10.5194/acp-5-1473-2005, 2005.

Schmidt, T., Wickert, J., Beyerle, G., and Heise, S.: Global tropopause height trends estimated from GPS radio occultation data, Geophys. Res. Lett., 35, L11806, https://doi.org/10.1029/2008GL034012, 2008.

Schmidt, T., Wickert, J., and Haser, A.: Variability of the upper troposphere and lower stratosphere observed with GPS radio occultation bending angles and temperatures, Adv. Space Res., 46, 150-161, https://doi.org/10.1016/j.asr.2010.01.021, 2010.

Schreiner, W., Rocken, C., Sokolovskiy, S., Syndergaard, S., and Hunt, D.: Estimates of the precision of GPS radio occultations from the COSMIC/FORMOSAT-3 mission, Geophys. Res. Lett., 34, L04808, https://doi.org/10.1029/2006GL027557, 2007.

Sokolovskiy, S. V.: Tracking tropospheric radio occultation signals from low Earth orbit, Radio Sci., 36, 483-498, 2001.

Sokolovskiy, S. V., Rocken, C., Lenschow, D. H., Kuo, Y.H., Anthes,R. A., Schreiner, W. S., and Hunt, D. C.: Observing the moist troposphere with radio occultation signals from COSMIC, Geophys. Res. Lett., 34, L18802, https://doi.org/10.1029/2007GL030458, 2007.

Sokolovskiy, S., Rocken, C., Schreiner, W., Hunt, D. C., and Johnson, J.: Postprocessing of L1 GPS radio occultation signals recorded in open-loop mode, Radio Sci., 44, RS2002, https://doi.org/10.1029/2008RS003907, 2009.

Steiner, A. K., Kirchengast, G., and Ladreiter, H. P.: Inversion, error analysis, and validation of GPS/MET occultation data, Ann. Geophys., 17, 122-138, https://doi.org/10.1007/s00585999-0122-5, 1999.

Steiner, A. K., Kirchengast, G., Foelsche, U., Kornblueh, L., Manzini, E., and Bengtsson, L., GNSS occultation sounding for climate monitoring, Phys. Chem. Earth (A), 26, 113-124, 2001.

Steiner, A. K., Kirchengast, G., Lackner, B. C., Pirscher, B., Borsche, M., and Foelsche, U.: Atmospheric temperature change detection with GPS radio occultation 1995 to 2008, Geophys. Res. Lett., 36, L18702, https://doi.org/10.1029/2009GL039777, 2009.

Steiner, A. K., Lackner, B. C., Ladstädter, F., Scherllin-Pirscher, B., Foelsche, U., and Kirchengast, G.: GPS radio occultation for cli- 
mate monitoring and change detection, Radio Sci., 46, RS0D24, https://doi.org/10.1029/2010RS004614, 2011.

Steiner, A. K., Hunt, D., Ho, S.-P., Kirchengast, G., Mannucci, A. J., Scherllin-Pirscher, B., Gleisner, H., von Engeln, A., Schmidt, T., Ao, C., Leroy, S. S., Kursinski, E. R., Foelsche, U., Gorbunov, M., Heise, S., Kuo, Y.-H., Lauritsen, K. B., Marquardt, C., Rocken, C., Schreiner, W., Sokolovskiy, S., Syndergaard, S., and Wickert, J.: Quantification of structural uncertainty in climate data records from GPS radio occultation, Atmos. Chem. Phys., 13, 1469-1484, https://doi.org/10.5194/acp13-1469-2013, 2013.

Sun Y. Q., Liu C. L., Du Q. F., Wang X. Y., Bai W. H., Kirchengast G., Xia J. M., Meng X. G., Wang D. W., Cai Y. R., Zhao D. Y., Wu C. J., Li W., and Liu C.: Global Navigation Satellite System Occultation Sounder II (GNOS II), IGARSS 2017, Fort Worth, IEEE Xplore, 2017 IEEE International Geoscience and Remote Sensing Symposium (IGARSS), 11891192, https://doi.org/10.1109/IGARSS.2017.8127170, 2017.

Syndergaard, S.: On the ionosphere calibration in GPS radio occultation measurements, Radio Sci., 35, 865-883, https://doi.org/10.1029/1999rs002199, 2000.

Von Engeln, A., Healy, S., Marquardt, C., Andres, Y., and Sancho, F.: Validation of operational GRAS radio occultation data, Geophys. Res. Lett., 36, L17809, https://doi.org/10.1029/2009GL039968, 2009.

Vorob'ev, V. V. and Krasil'nikova, T. G.: Estimation of the accuracy of the atmospheric refractive index recovery from doppler shift measurements at frequencies used in the NAVSTAR system, Phys. Atmos. Ocean, 29, 602-609, 1994.

Wang, S. Z., Zhu, G. W., Bai, W. H., Liu, C. L., Sun, Y. Q., Du, Q. F., Wang, X. Y., Meng, X. G., Yang, G. 1., Yang, Z. D., Zhang, X. X., Bi, Y. M., Wang, D. W., Xia, J. M., Wu, D., Cai, Y. R., and Han, Y.: For the first time fengyun3 $\mathrm{C}$ satellite-global navigation satellite system occultation sounder achieved spaceborne Bei Dou system radio occultation, Acta Phys. Sin., 64, 089301, $1-7,2015$

Wang, X. Y., Sun, Y. Q., Bai, W. H., Du, Q. F., Wang, D. W., Wu, D., Yu, Q. L., and Han, Y.: Simulation of number and distribution of Compass occultation events, Chinese J. Geophys., 56, 25212530, 2013.

Wang, X. Y., Sun, Y. Q., Du, Q. F., Bai, W. H., Wang, D. W., Cai, Y. R., Wu, D., and Yu, Q. L.: GNOS - Radio Occultation Sounder on Board of Chinese FY3 Satellites, IGARSS 2014, Quebec, 4982-4985, 2014.

Wang, X. Y., Sun, Y. Q., Du, Q. F., Wang, D. W., Wu, D., Cai, Y. R., Wu, C. J., Bai, W. H., Xia, J. M., and Li, W.: An Integrated GNSS Remote Sensing Instrument and Its First GNSSR Airborne Experiment, IGARSS 2016, Beijing, 4827-4830, 2016.
Ware, R., Exner, M., Feng, D., Gorbunov, M., Hardy, K., Herman, B., Kuo, Y., Meehan, T., Melbourne, W., Rocken, C., Schreiner, W., Sokolovskiy, S., Solheim, F., Zou, X., Anthes, R., Businger, S., and Trenberth, K.: GPS Sounding of the atmosphere from Low Earth Orbit: Preliminary results, B. Am. Meteorol. Soc., 77, 19-40, https://doi.org/10.1175/15200477(1996)077<0019:GSOTAF>2.0.CO;2, 1996.

Wickert, J.: Amplitude variations in GPS signals as a possible indicator of ionospheric structures, Geophys. Res. Lett., 31, L24801, https://doi.org/10.1029/2004gl020607, 2004.

Wickert, J., Reigber, C., Beyerle, G., Koenig, R., Marquardt, C., Schmidt, T., and Grunwaldt, L., Galas, R., Meehan, T. K., Melbourne, W. G., and Hocke, K.: Atmosphere sounding by GPS radio occultation: First results from CHAMP, Geophys. Res. Lett., 28, 3263-3266, https://doi.org/10.1029/2001GL013117, 2001.

Wickert, J., Beyerle, G., Hajj, G. A., Schwieger, V., and Reigber, C.: GPS radio occultation with CHAMP: Atmospheric profiling utilizing the space-based single difference technique, Geophys. Res. Lett., 29, 28-1-28-4, https://doi.org/10.1029/2001GL013982, 2002.

Wickert, J., Beyerle, G., König, R., Heise, S., Grunwaldt, L., Michalak, G., Reigber, Ch., and Schmidt, T.: GPS radio occultation with CHAMP and GRACE: A first look at a new and promising satellite configuration for global atmospheric sounding, Ann. Geophys., 23, 653-658, https://doi.org/10.5194/angeo-23-6532005, 2005.

Wu, X., Hu, X., Gong, X., Zhang, X., and Wang, X.: Analysis of inversion errors of ionospheric radio occultation, GPS Solutions, 13, 231-239, https://doi.org/10.1007/s10291-008-0116-x, 2009.

Xiong, C., Lu, C., Zhu, J., and Ding, H.: Orbit determination using real tracking data from FY3C-GNOS, Adv. Space Res., 60, 543556, 2017.

Yang, G. L., Sun Y. Q., Bai, W. H., Zhang, X. X., Liu, C. L., Meng, X. G., Bi, Y. M., Wang, D. W., and Zhao, D. Y.: Validation results of $\mathrm{NmF} 2$ and $\mathrm{hmF} 2$ derived from ionospheric density profiles of GNOS on FY-3C Satellite, Science China Technological Sciences, 59, 183-190, https://doi.org/10.1007/s11431-015-5920-2, 2017.

Yue, X., Schreiner, W. S., Zeng, Z., Kuo, Y.-H., and Xue, X.: Case study on complex sporadic E layers observed by GPS radio occultations, Atmos. Meas. Tech., 8, 225-236, https://doi.org/10.5194/amt-8-225-2015, 2015.

Zhao, Q., Wang, C., Guo, J., Yang, G., Liao, M., Ma, H., and Liu, J.: Enhanced orbit determination for BeiDou satellites with FengYun-3C onboard GNSS data, GPS Solutions, 21, 11791190, 2017. 